\title{
Cryopyrin activates the inflammasome in response to toxins and ATP
}

\author{
Sanjeev Mariathasan ${ }^{1}$, David S. Weiss ${ }^{4}$, Kim Newton $^{1}$, Jacqueline McBride ${ }^{3}$, Karen O'Rourke ${ }^{1}$, \\ Meron Roose-Girma ${ }^{2}$, Wyne P. Lee ${ }^{3}$, Yvette Weinrauch ${ }^{5}$, Denise M. Monack ${ }^{4}$ \& Vishva M. Dixit ${ }^{1}$
}

A crucial part of the innate immune response is the assembly of the inflammasome, a cytosolic complex of proteins that activates caspase- 1 to process the proinflammatory cytokines interleukin (IL)-1 $\beta$ and IL-18. The adaptor protein ASC is essential for inflammasome function ${ }^{1,2}$, binding directly to caspase-1 (refs 3,4$)$, but the triggers of this interaction are less clear. ASC also interacts with the adaptor cryopyrin (also known as NALP3 or CIAS1) ${ }^{5,6}$. Activating mutations in cryopyrin are associated with familial cold autoinflammatory syndrome, Muckle-Wells syndrome and neonatal onset multisystem inflammatory disease, diseases that are characterized by excessive production of IL- $1 \beta^{5,7}$. Here we show that cryopyrin-deficient macrophages cannot activate caspase- 1 in response to Toll-like receptor agonists plus ATP, the latter activating the $\mathrm{P} 2 \mathrm{X}_{7}$ receptor to decrease intracellular $\mathrm{K}^{+}$ levels $s^{8,9}$. The release of IL-1 $\beta$ in response to nigericin, a potassium ionophore, and maitotoxin, a potent marine toxin, was also found to be dependent on cryopyrin. In contrast to $A s c^{-1-}$ macrophages, cells deficient in the gene encoding cryopyrin $\left(\right.$ Cias $\left.^{-/-}\right)$activated caspase- 1 and secreted normal levels of IL-1 $\beta$ and IL-18 when infected with Gram-negative Salmonella typhimurium or Francisella tularensis. Macrophages exposed to Gram-positive Staphylococcus aureus or Listeria monocytogenes, however, required both ASC and cryopyrin to activate caspase-1 and secrete IL-1 $\beta$. Therefore, cryopyrin is essential for inflammasome activation in response to signalling pathways triggered specifically by ATP, nigericin, maitotoxin, $S$. aureus or L. monocytogenes.

Cryopyrin-deficient mice (Supplementary Fig. S1) were generated by gene targeting to investigate the role of cryopyrin in inflammatory responses to pathogen-derived molecules. Cryopyrin-deficient $\left(\right.$ Cias $\left.^{-l-}\right)$ macrophages stimulated with the Toll-like receptor-4 (TLR4) agonist lipopolysaccharide (LPS) phosphorylated Iк $\mathrm{B} \alpha$ and ERK normally (Fig. 1a), and they secreted normal amounts of TNF- $\alpha$ (Fig. 1b), IL-12 p40 (Fig. 1c), IL-6 and IL-10 (data not shown). Similar results were obtained using the TLR2 agonists $\mathrm{Pam}_{3} \mathrm{CSK}_{4}$ and heat-killed L. monocytogenes (HKLM) (data not shown). Our results show that cryopyrin is dispensable for NF- $\mathrm{B}$ signalling by TLR 2 and TLR4 in macrophages.

Because mutant variants of cryopyrin are associated with diseases in which IL- $1 \beta$ is produced in excess ${ }^{5-7}$, we measured IL- $1 \beta$ released from Cias $1^{-l-}$ macrophages treated with TLR agonists and ATP (Fig. 1d). TLR agonists induce pro-IL-1 $\beta$ synthesis and ATP stimulates caspase-1-dependent cleavage and secretion of IL-1 $\beta^{10}$. In contrast to wild-type macrophages, which secreted readily detectable amounts of IL-1 $\beta$ and IL-18 in response to ATP plus ultra-pure LPS, $\mathrm{Pam}_{3} \mathrm{CSK}_{4}$, HKLM, R848 (TLR7/8 agonist), or CpG oligonucleotides (TLR9 agonist), Cias $1^{-1-}$ macrophages secreted negligible amounts of these cytokines (Fig. 1d, e). As shown previously ${ }^{1,11}, A s c^{-1-}$ macrophages exhibited a similar defect in IL-1 $\beta$ and IL-18 production (Fig. 1d, e). Macrophages from heterozygous Cias $1^{+/-}$mice secreted intermediate amounts of IL- $1 \beta$ and IL-18. C3H/HeJ macrophages expressing a non-functional form of TLR4 (ref. 12) secreted IL-1 $\beta$ and IL-18 in response to ATP plus either $\mathrm{Pam}_{3} \mathrm{CSK}_{4}$ or HKLM, but not LPS, demonstrating that our LPS was pure and not contaminated with other TLR agonists (Fig. 1d).

To determine whether IL-1 $\beta$ secretion from Cias ${ }^{-1-}$ macrophages was defective due to impaired pro-IL-1 $\beta$ synthesis and/or impaired caspase- 1 activation, we immunoprecipitated $\left[{ }^{35} \mathrm{~S}\right]$-methioninelabelled pro-IL-1 $\beta$ from LPS-primed macrophages. Wild-type, Cias $^{+/-}$and Cias1 ${ }^{-1-}$ macrophages produced comparable amounts of pro-IL-1 $\beta$ (Fig. 1f, left panel), indicating that defective IL-1 $\beta$ secretion from Cias $1^{-1-}$ cells was not due to impaired pro-IL-1 $\beta$ synthesis. Unlike their wild-type counterparts, however, Cias ${ }^{-1-}$ macrophages did not cleave pro-IL-1 $\beta$ after ATP treatment (Fig. 1f, right panel). This finding suggested that cryopyrin is essential for ATP-induced caspase- 1 activation. A further indication of caspase- 1 activation is its autocatalytic processing into p20 and p10 subunits. Western blotting for caspase-1 after LPS plus ATP treatment revealed the p10 and p20 subunits in wild-type but not Cias $1^{-/-}$macrophages (Fig. 1g). Thus, cryopyrin is essential for activation of caspase-1 in response to LPS plus ATP. Notably, ATP was necessary but not sufficient for caspase-1 activation (Fig. 1g). TLR signalling is probably needed for expression of essential inflammasome components. For example, LPS stimulation of TLR4 increases expression of caspase-11, and analyses of caspase-11-deficient mice and cells demonstrate that caspase-11 is essential for inflammasome function ${ }^{13}$.

To test whether the role of ATP in cryopyrin- and ASC-dependent caspase- 1 activation relates to its ability to stimulate the $\mathrm{P}_{2} \mathrm{X}_{7}$ receptor $^{9}$ and thereby reduce intracellular $\mathrm{K}^{+}$(ref. 8), we treated TLR-primed macrophages from wild-type, $\mathrm{Asc}^{-1-}$ and $\mathrm{Cias}^{-1-}$ mice with nigericin or maitotoxin to deplete cytosolic $\mathrm{K}^{+}$(refs 14, 15). Wild-type macrophages primed with LPS or $\mathrm{Pam}_{3} \mathrm{CSK}_{4}$ secreted IL-1 $\beta$ and IL-18 in response to nigericin (Fig. 2a, b) or maitotoxin (Fig. 2c, d). By contrast, neither $A_{s c^{-I-}}$ nor Cias ${ }^{-l-}$ macrophages released significant IL-1 $\beta$ or IL-18. Our data therefore show that ASC and cryopyrin are essential for IL-1 $\beta$ and IL-18 production by TLR-primed macrophages treated with agents that deplete intracellular $\mathrm{K}^{+}$. Neither nigericin nor maitotoxin alone induced IL-1 $\beta$ release (Supplementary Fig. S2). Again, TLR signalling is probably required not only for the induction of pro-IL-1 $\beta$ (Fig. 1f) but also for expression of other proteins that are essential for inflammasome function.

To determine whether cryopyrin is essential for inflammation

${ }^{1}$ Molecular Oncology Department, ${ }^{2}$ Physiology Department, ${ }^{3}$ Immunology Department, Genentech Inc, 1 DNA Way, South San Francisco, California 94080 , USA. ${ }^{4}$ Departments of Microbiology and Immunology, Stanford University School of Medicine, Stanford, California 94305, USA. ${ }^{5}$ Department of Microbiology, New York University School of Medicine, New York, New York 10016, USA. 
in vivo, wild-type and Cias $1^{-1-}$ mice were injected with a lethal dose of LPS to induce caspase-1-dependent endotoxic shock ${ }^{16}$. All of the wild-type mice died within $48 \mathrm{~h}$, whereas only $\sim 30 \%$ of the Cias $1^{-1-}$ mice had died after $72 \mathrm{~h}$ (Fig. 2e). Correlating with their enhanced survival, Cias $1^{-1-}$ mice had markedly less serum IL-1 $\beta$ and IL-18 than the wild-type mice (Fig. 2f). It is unclear why exogenous ATP is not required for IL-1 $\beta$ and IL-18 secretion in vivo. We speculate that other cell types impacted by LPS in vivo provide the ATP needed to engage the $\mathrm{P}_{2} \mathrm{X}_{7}$ receptor. Our results demonstrate that cryopyrin, like ASC, is also an important mediator of LPS-induced endotoxic shock $^{1}$.

A previous study suggested that bacterial muramyl dipeptide (MDP) can activate a cryopyrin-containing inflammasome ${ }^{17}$. MDP is also the ligand for NOD2, which resembles cryopyrin in that it possesses a nucleotide binding domain and leucine-rich repeats ${ }^{7,18-20}$. Mutated NOD2 has been linked to Crohn's disease ${ }^{7}$. MDP induced phosphorylation of $\operatorname{I\kappa B} \alpha$ and ERK in wild-type and Cias1 $1^{-1-}$ macrophages but, in agreement with published results ${ }^{19}, \mathrm{Nod} 2^{-/-}$ macrophages were unresponsive (Fig. 3a). NOD2-deficiency, however, did not impact on LPS-induced phosphorylation of I $\mathrm{B} \alpha$ and ERK, or subsequent Iк $B \alpha$ degradation (Fig. 3a). In terms of cytokine production, MDP enhanced LPS-induced secretion of TNF and IL-12 p40 by wild-type and Cias $1^{-1-}$ macrophages but not Nod $2^{-7-}$ macrophages (Fig. 3b, c). Because cryopyrin was essential for LPS- plus ATP-induced IL- $1 \beta$ secretion, we could not assess whether MDP increased IL-1 $\beta$ production in wild-type cells by engaging cryopyrin (Fig. 3d). Our data indicate that cryopyrin is dispensable for MDP-induced activation of NF-кB and ERK, and confirm a crucial role for cryopyrin in ATP-induced activation of the macrophage inflammasome.

Next we determined whether cryopyrin is required for caspase-1 activation and IL-1 $\beta$ release when macrophages are infected by specific bacterial pathogens. Unlike ASC, cryopyrin was dispensable for normal caspase- 1 activation, IL- $1 \beta$ secretion and macrophage a
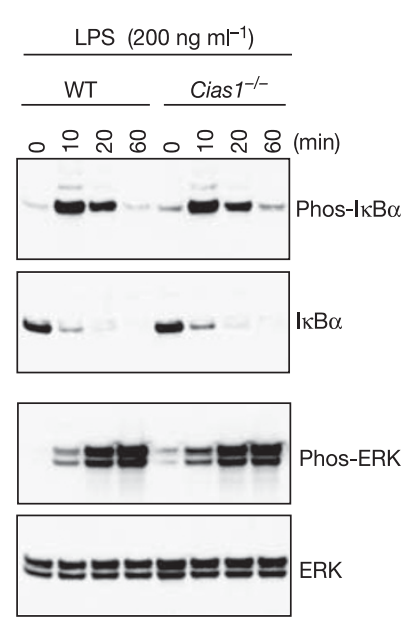

b
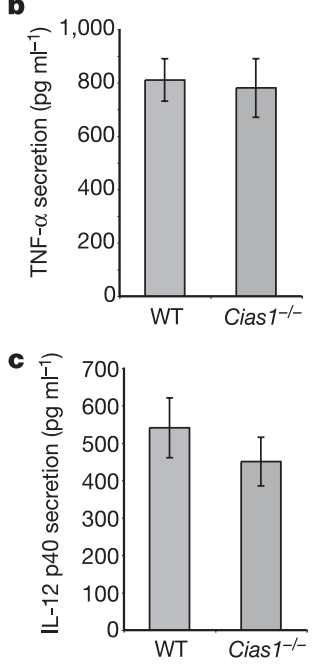

e
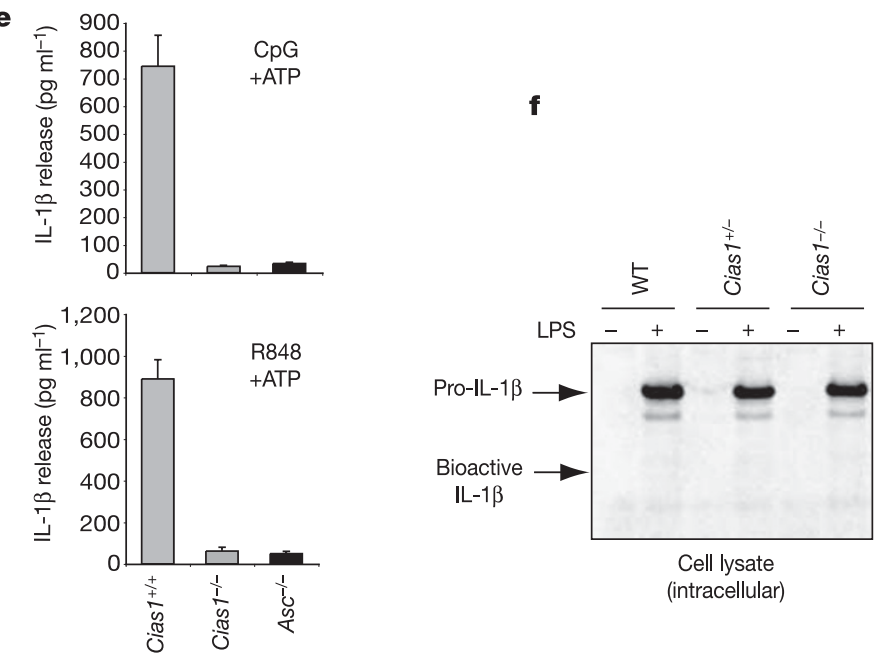

Figure 1 | Cryopyrin is essential for caspase-1 activation and IL-1 $\beta$ secretion in response to TLR agonists and ATP. a, Western blot analysis of phosphorylated and total IкB $\alpha$ and ERK in wild-type (WT) and Cias $1^{-1}$ bone-marrow-derived macrophages stimulated with LPS. b, c, TNF (b) and IL-12 p40 (c) secretion by peritoneal macrophages cultured for $16 \mathrm{~h}$ with LPS. d, Macrophages primed for $16 \mathrm{~h}$ with LPS, $\mathrm{Pam}_{3} \mathrm{CSK}_{4}$, or HKLM were then pulsed with ATP. IL-1 $\beta$ or IL-18 released in the next $3 \mathrm{~h}$ is shown. ND, not detected. e, IL-1 $\beta$ secretion by macrophages primed with CpG DNA or R848 and then pulsed with ATP. Bars in b-e represent the mean \pm s.d. of
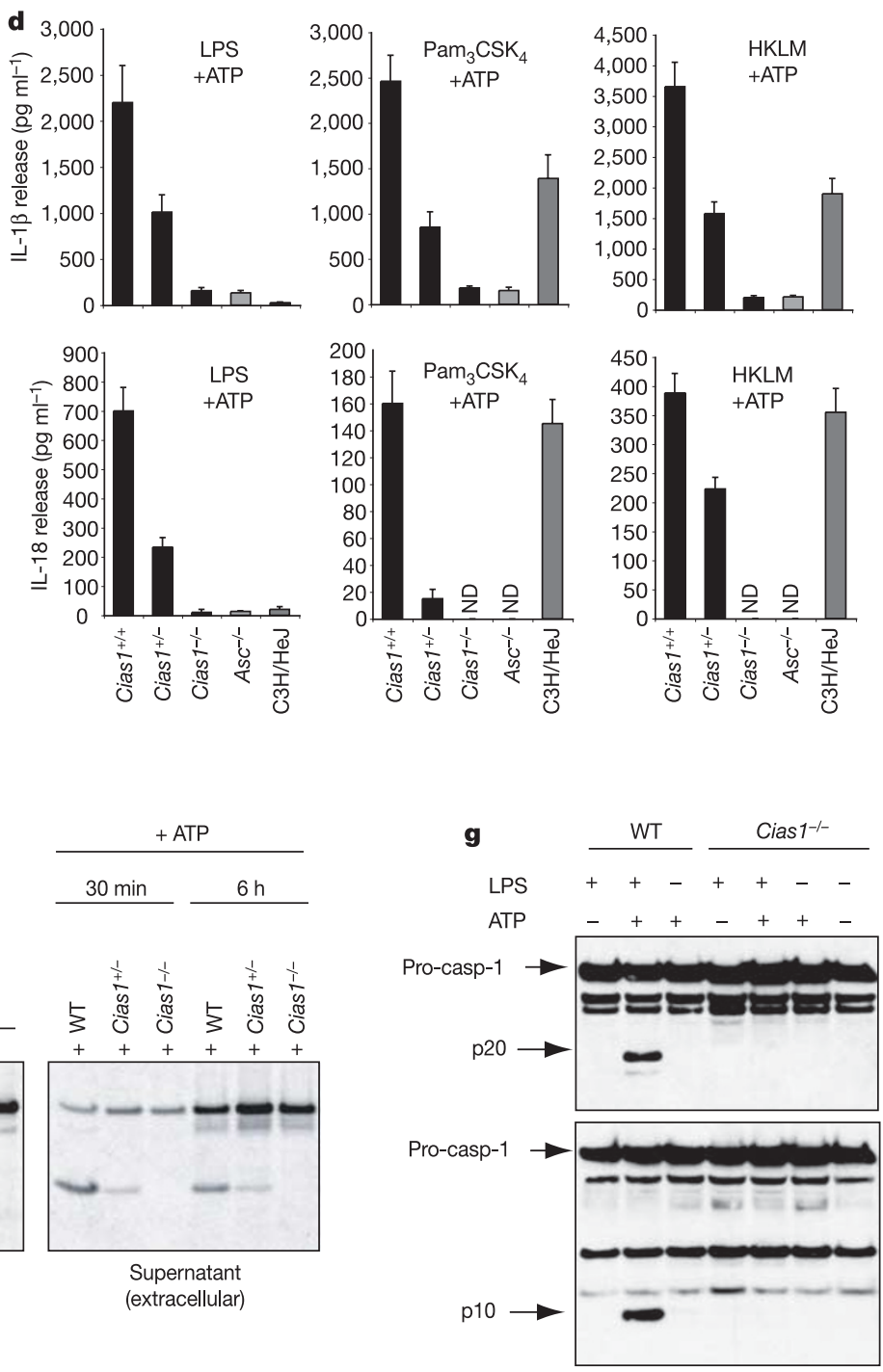

triplicate wells. Results are representative of four independent experiments. f, Immunoprecipitation of $\left[{ }^{35} S\right]$-labelled pro-IL-1 $\beta$ and IL-1 $\beta$ from macrophages treated with LPS (left panel). Pro-IL-1 $\beta$ and IL-1 $\beta$ secreted after subsequent ATP treatment were immunoprecipitated from culture supernatants (right panel). g, Western blot analysis of caspase-1 in peritoneal macrophages stimulated with LPS for $16 \mathrm{~h}$ and then pulsed with ATP for $20 \mathrm{~min}$. All in vitro experiments were performed with ultra-pure LPS. 

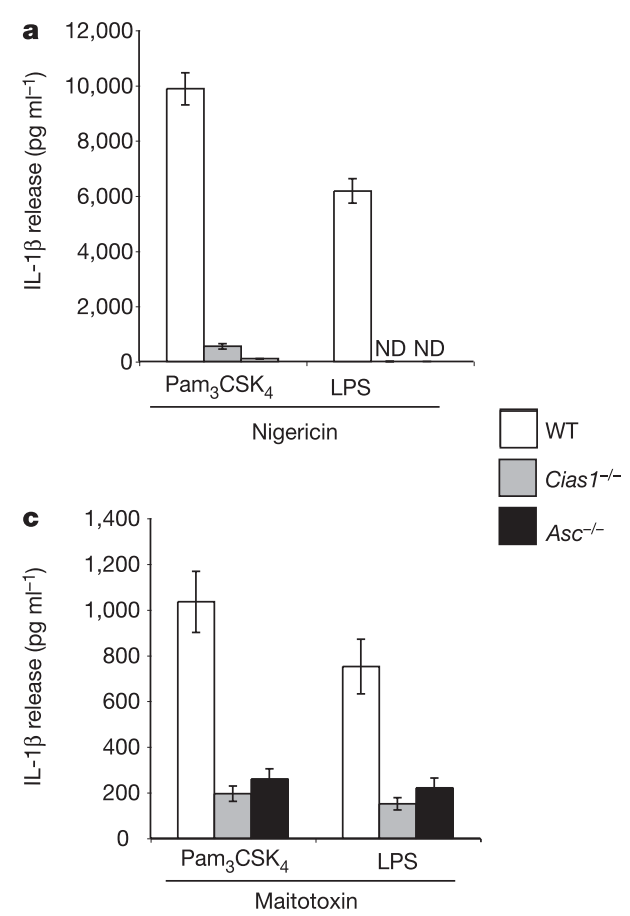
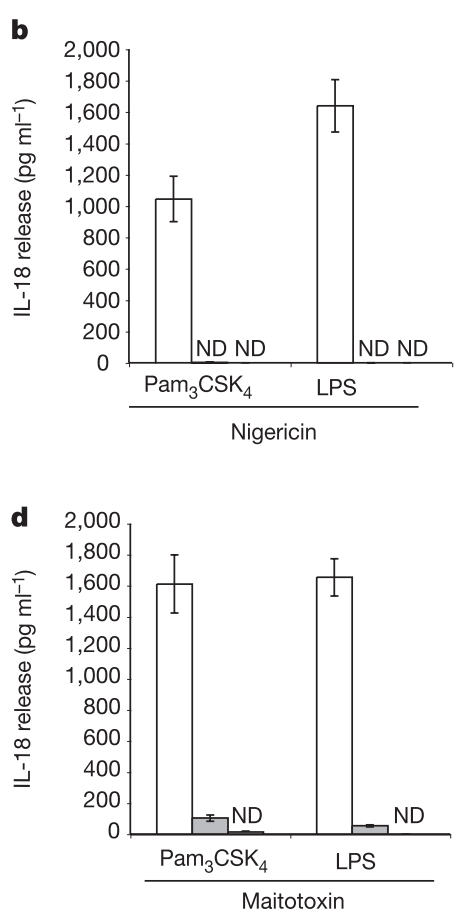
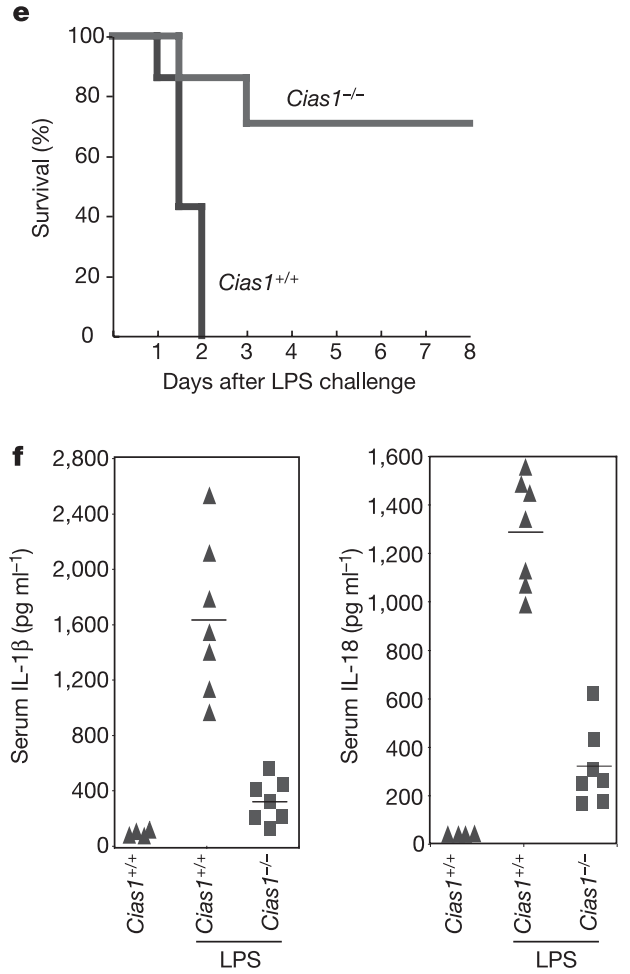

Figure 2 Cryopyrin is essential for caspase-1 activation and IL-1 $\beta$ secretion in response to TLR agonists plus nigericin or maitotoxin. a-d, Wild-type, Cias $1^{-1-}$ and $A s c^{-1-}$ macrophages were primed with $\mathrm{Pam}_{3} \mathrm{CSK}_{4}$ or ultra-pure LPS and then treated with nigericin $(\mathbf{a}, \mathbf{b})$ or maitotoxin $(\mathbf{c}, \mathbf{d})$. IL-1 $\beta$ (a, c) and IL-18 (b, d) release was measured by ELISA. Bars in a-d represent the mean \pm s.d. of triplicate wells. Results are representative of three independent experiments. ND, not detected. e, Survival of 8-week-old

wild-type $(n=7)$ or Cias $^{-1-}(n=7)$ female mice injected intraperitoneally with crude LPS ( $40 \mathrm{mg} \mathrm{kg}^{-1}$ of body weight) on day $0 . \mathrm{f}$, Levels of IL-1 $\beta$ and IL-18 in the serum of the mice in e at $3 \mathrm{~h}$ after injection. Lines indicate the mean serum level (IL-1 $\beta$ : WT, 1,581 $\mathrm{pg} \mathrm{ml}^{-1} ; \mathrm{Cias}^{-/-}$, $304 \mathrm{pg} \mathrm{ml}^{-1}, P=0.001$; IL-18: WT, 1,321 $\mathrm{pg} \mathrm{ml}^{-1}$; Cias1 ${ }^{-/-}, 329 \mathrm{pg} \mathrm{ml}^{-1}$, $P=0.0004)$.

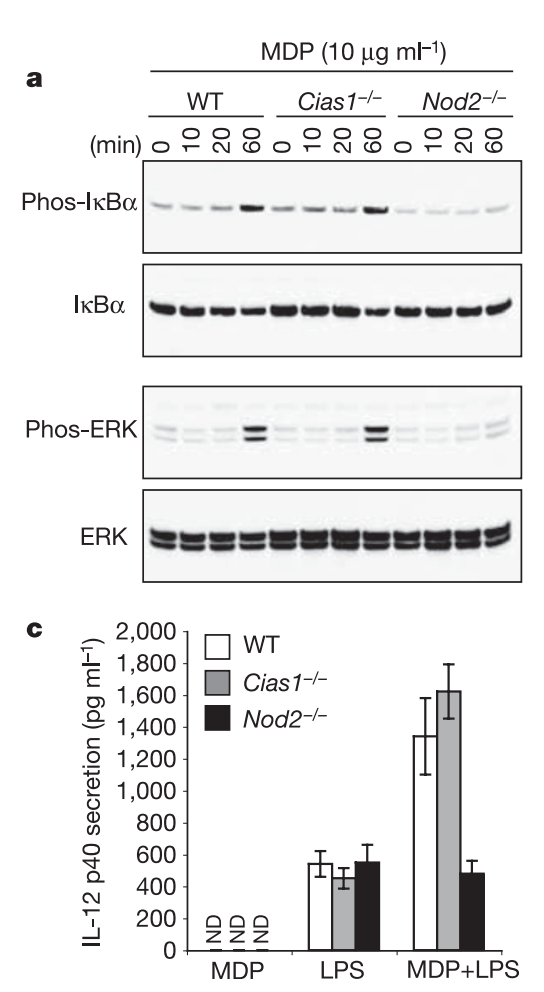

Figure 3 | MDP triggers NOD2-dependent, cryopyrin-independent NF- $\mathrm{k}$ and ERK signalling. a, Western blot analysis of phosphorylated or total I $\mathrm{KB} \alpha$ and ERK in wild-type, Cias $1^{-1-}$ and $\mathrm{Nod} 2^{-1-}$ macrophages stimulated with MDP or LPS. b-d, Secretion of TNF (b), IL-12 p40 (c), or
LPS

$\frac{\left(200 \mathrm{ng} \mathrm{ml}^{-1}\right)}{\mathrm{Nod}^{-1-}}$
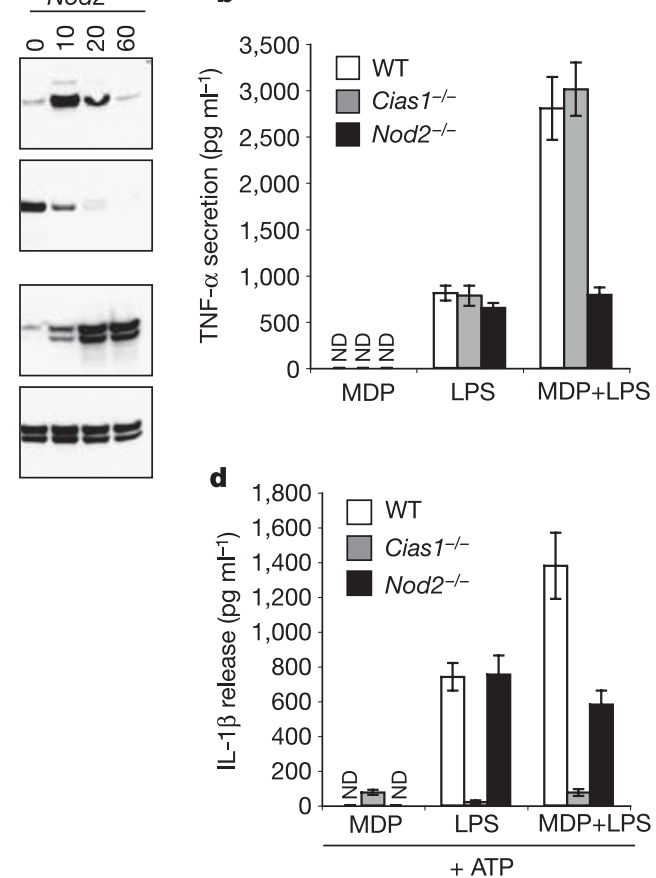

IL-1 $\beta$ (d) by bone-marrow-derived macrophages treated with MDP and/or LPS. Macrophages in $\mathbf{d}$ were also pulsed with ATP. ND, not detected. Bars represent the mean \pm s.d. of triplicate wells. Results are representative of three independent experiments. 
cell death in response to Gram-negative S. typhimurium (Fig. 4a, b) or F. tularensis (Fig. 4c, d) (Supplementary Fig. S4). As shown previously ${ }^{1,21}$, macrophages infected by $S$. typhimurium also require the adaptor protein Ipaf to activate caspase-1 (Fig. 4a). ASC and cryopyrin were essential for caspase- 1 activation and secretion of IL-1 $\beta$ or IL-18 when macrophages were cultured with Gram-positive S. aureus (Fig. $4 \mathrm{e}-\mathrm{g}$ ) or L. monocytogenes (Fig. $4 \mathrm{~h}-\mathrm{l}$ ), but NOD2 was dispensable (data not shown). ASC or cryopyrin deficiency caused a specific defect in IL-1 $\beta$ and IL-18 release because $A s c^{-1-}$ and Cias $1^{-l-}$ macrophages infected by L. monocytogenes and S. aureus yielded similar amounts of TNF to wild-type macrophages (Fig. $4 \mathrm{k}$ and data not shown). Macrophages cultured with $L$. monocytogenes deficient for the toxin listeriolysin O did not secrete IL-1 $\beta$ (Fig. 4l), so we speculate that listeriolysin $\mathrm{O}$ perturbs intracellular $\mathrm{K}^{+}$levels similar to extracellular ATP, nigericin and maitotoxin. Furthermore, live bacteria seem to be required because heat-killed Listeria monocytogenes (HKLM) induced very little IL-1 $\beta$ secretion (data not shown). S. aureus deficient in alpha-, beta- or gamma-toxin induced comparable IL-1 $\beta$ secretion to wild-type S. aureus (Supplementary
Fig. S5), indicating that other $S$. aureus toxins may contribute to caspase- 1 activation.

Our results suggest that the caspase- 1 inflammasome is a dynamic entity that is assembled from different adaptor proteins in a stimulus-dependent manner (Fig. 4m). We show that cryopyrin is essential for inflammasome activation in response to signalling pathways triggered by specific bacterial infections and to treatments that deplete intracellular $\mathrm{K}^{+}$. Ipaf and perhaps other members of the large NALP family of proteins might substitute for cryopyrin upon infection with Gram-negative bacteria such as S. typhimurium and F. tularensis. The cryopyrin-dependent response to extracellular ATP may represent a physiological response that occurs when ATP is released by dying cells and degranulating platelets. Future studies will need to address how activating mutations in cryopyrin circumvent the normal regulation of the inflammasome to produce inflammatory diseases such as familial cold autoinflammatory syndrome, Muckle-Wells syndrome and neonatal onset multisystem inflammatory disease $\mathrm{e}^{22-25}$. An intriguing possibility is that low level bacterial infection coupled with a dysregulated
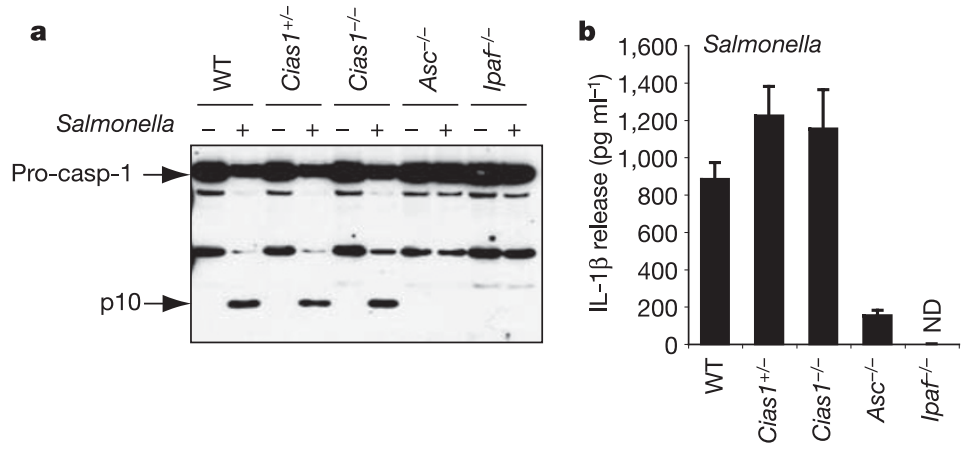

g
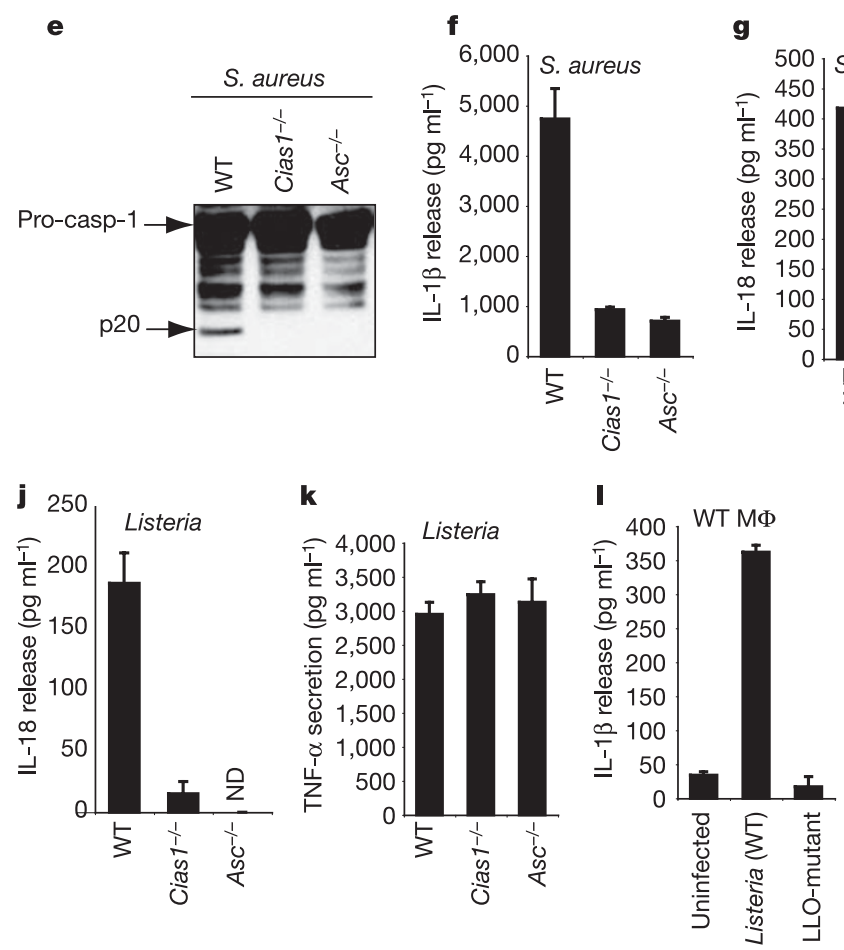

Figure 4 | L. monocytogenes and S. aureus induce cryopyrin-dependent caspase- 1 activation and IL-1 $\beta$ secretion. a-k, Wild-type, Cias ${ }^{-1-}$, Asc $^{-1-}$ and Ipaf ${ }^{-1-}$ macrophages pre-treated with LPS were infected with S. typhimurium (a, b), F. tularensis $(\mathbf{c}, \mathbf{d})$, S. aureus $(\mathbf{e}-\mathbf{g})$ or L. monocytogenes (h-k) and immunoblotted for the $\mathbf{p} 10$ or $\mathbf{p} 20$ subunit of caspase-1 (a, $\mathbf{c}, \mathbf{e}, \mathbf{h})$. IL-1 $\beta$ (b, d, $\mathbf{f}, \mathbf{i})$, IL-18 $(\mathbf{g}, \mathbf{j})$ or TNF (k) secretion was measured by ELISA. ND, not detected. I, IL-1 $\beta$ released from wild-type macrophages pre-treated c
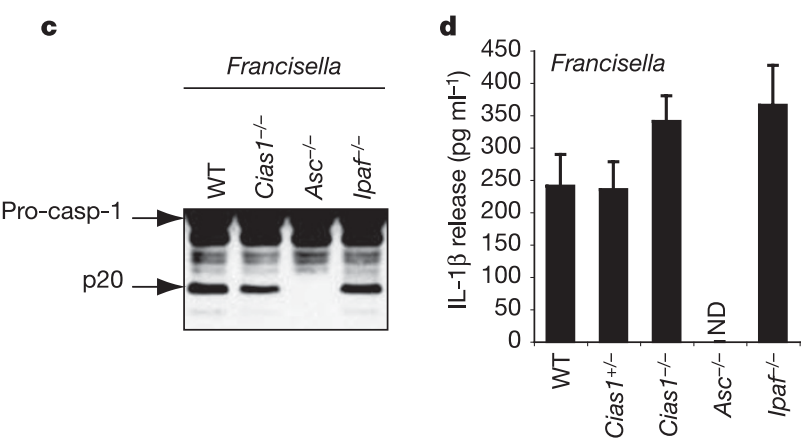

h
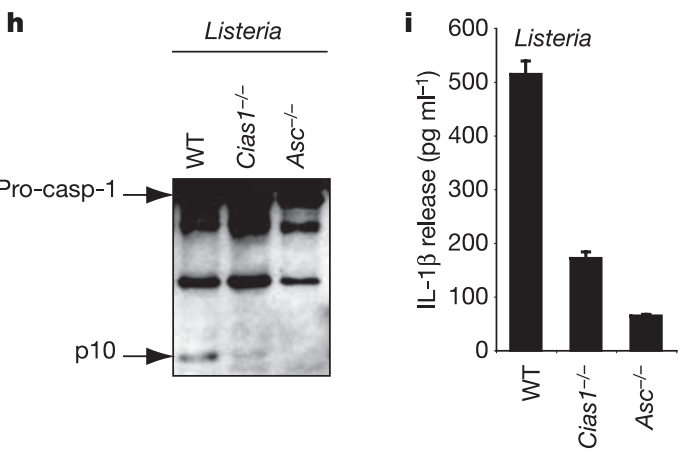

m
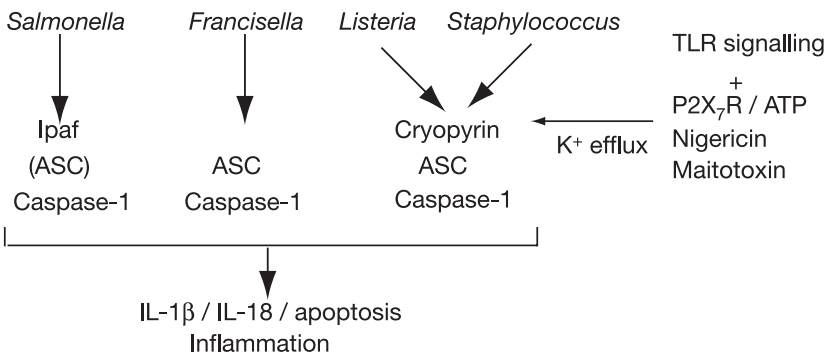

with LPS and infected with wild-type $L$. monocytogenes or a listeriolysin O (LLO) mutant. All data are representative of 2-4 independent experiments. Bars represent the mean \pm s.d. of triplicate wells. LPS pre-treatment was not essential for IL-1 $\beta$ release (Supplementary Fig. 6). Cell viability after infection is shown in Supplementary Fig. 4. m, Model for the differential activation of the caspase-1 inflammasome by various pathogens and toxins. 
cryopyrin response triggers the symptoms associated with these diseases.

\section{METHODS}

Cias1, Nod2, Asc and Ipaf mutant cells and mice. $A s c^{-1-}$ and Ipaf ${ }^{-1-}$ mice have been described ${ }^{1}$. Cias1 ${ }^{-1-}$ and Nod2 $2^{-1-}$ mice are described in Supplementary Figs 1 and 3. Macrophage and bacterial cultures are described in detail in the Supplementary Methods. Briefly, macrophages primed overnight with $50 \mathrm{ng} \mathrm{ml}^{-1}$ ultra-pure LPS were infected at a multiplicity of infection of 50 (30 for F. tularensis) for $1 \mathrm{~h}$ (S. typhimurium), $2.5 \mathrm{~h}$ (L. monocytogenes), $3 \mathrm{~h}$ (S. aureus) or $5 \mathrm{~h}$ (F. tularensis).

Immunoprecipitation, western blotting and pulse-chase analysis. IL- $1 \beta$ was immunoprecipitated with goat anti-mouse IL-1 $\beta$ (clone AF-401-NA; R\&D Systems) and blotted with hamster anti-mouse IL-1 $\beta$ (clone B122; Becton Dickinson). For pulse-chase analyses, macrophages were treated with $1 \mu \mathrm{g} \mathrm{ml}^{-1}$ ultra-pure LPS for $3 \mathrm{~h}$ and then labelled with $200 \mu \mathrm{Ci} \mathrm{ml}^{-1}\left[{ }^{35} \mathrm{~S}\right]-$ methionine (ICN) for $45 \mathrm{~min}$. Labelled cells were treated with $5 \mathrm{mM}$ ATP (Sigma) for $30 \mathrm{~min}$ and then placed in fresh medium. Caspase-1 was blotted with rat anti-mouse caspase-1 (clone 4B4; Genentech) and rabbit anti-caspase-1 (sc-514; Santa Cruz Biotechnology). Phospho-IkB $\alpha$ (Ser32), IкB $\alpha$, phospho-ERK and ERK antibodies were from Cell Signalling Technology.

Cytokine ELISAs. TNF and IL-12 p40 secretion were measured by enzymelinked immunosorbent assay (ELISA; R\&D Systems) after $16 \mathrm{~h}$ of stimulation with $500 \mathrm{ng} \mathrm{ml}^{-1}$ ultra-pure LPS (List Biologicals), $100 \mathrm{ng} \mathrm{ml}^{-1} \mathrm{Pam}_{3} \mathrm{CSK}_{4}$ (Invivogen), $10^{8}$ bacteria per $\mathrm{ml} \mathrm{HKLM} \mathrm{(Invivogen),} 5 \mu \mathrm{M} \mathrm{CpG}$ oligonucleotide (Invivogen ODN1826), $100 \mathrm{ng} \mathrm{ml}^{-1} \mathrm{R} 848$ (Invivogen) or $10 \mu \mathrm{g} \mathrm{ml}^{-1} \mathrm{MDP}$ (Invivogen). The macrophages then were pulsed for 20 min with $5 \mathrm{mM}$ ATP, $20 \mu \mathrm{M}$ nigericin (Calbiochem), or $0.5 \mathrm{nM}$ maitotoxin (Dako) and cultured an additional $3 \mathrm{~h}$ for IL-1 $\beta$ and IL-18 secretion. Serum levels of IL-1 $1 \beta$ and IL-18 were determined $3 \mathrm{~h}$ after intraperitoneal injection with $40 \mathrm{mg} \mathrm{kg}^{-1}$ crude LPS (Escherichia coli serotype 0111:B4; Sigma).

Received 7 October; accepted 12 December 2005.

Published online 11 January 2006.

1. Mariathasan, S. et al. Differential activation of the inflammasome by caspaseadaptors ASC and Ipaf. Nature 430, 213-218 (2004)

2. Martinon, F., Burns, K. \& Tschopp, J. The inflammasome: a molecular platform triggering activation of inflammatory caspases and processing of prolL- $\beta$. Mol. Cell 10, 417-426 (2002)

3. Srinivasula, S. M. et al. The PYRIN-CARD protein ASC is an activating adaptor for caspase-1. J. Biol. Chem. 277, 21119-21122 (2002).

4. Wang, L. et al. PYPAF7, a novel PYRIN-containing Apaf1-like protein that regulates activation of $\mathrm{NF}-\mathrm{KB}$ and caspase-1-dependent cytokine processing. J. Biol. Chem. 277, 29874-29880 (2002).

5. Agostini, L. et al. NALP3 forms an IL-1ß-processing inflammasome with increased activity in Muckle-Wells autoinflammatory disorder. Immunity 20, 319-325 (2004).

6. Dowds, T. A., Masumoto, J., Zhu, L., Inohara, N. \& Nunez, G. Cryopyrininduced interleukin $1 \beta$ secretion in monocytic cells: enhanced activity of disease-associated mutants and requirement for ASC. J. Biol. Chem. 279, 21924-21928 (2004)

7. Ting, J. P. \& Davis, B. K. CATERPILLER: a novel gene family important in immunity, cell death, and diseases. Annu. Rev. Immunol. 23, 387-414 (2005).

8. Perregaux, D. \& Gabel, C. A. Interleukin-1ß maturation and release in response to ATP and nigericin. Evidence that potassium depletion mediated by these agents is a necessary and common feature of their activity. J. Biol. Chem. 269 15195-15203 (1994).
9. Solle, M. et al. Altered cytokine production in mice lacking $\mathrm{P} 2 \mathrm{X}_{7}$ receptors. J. Biol. Chem. 276, 125-132 (2001).

10. Hogquist, K. A., Nett, M. A., Unanue, E. R. \& Chaplin, D. D. Interleukin 1 is processed and released during apoptosis. Proc. Natl Acad. Sci. USA 88, 8485-8489 (1991).

11. Yamamoto, M. et al. ASC is essential for LPS-induced activation of procaspase-1 independently of TLR-associated signal adaptor molecules. Genes Cells 9, 1055-1067 (2004).

12. Poltorak, A. et al. Defective LPS signalling in $\mathrm{C} 3 \mathrm{H} / \mathrm{HeJ}$ and $\mathrm{C} 57 \mathrm{BL} / 10 \mathrm{ScCr}$ mice: mutations in TIr4 gene. Science 282, 2085-2088 (1998).

13. Wang, S. et al. Murine caspase-11, an ICE-interacting protease, is essential for the activation of ICE. Cell 92, 501-509 (1998).

14. Schilling, W. P., Wasylyna, T., Dubyak, G. R., Humphreys, B. D. \& Sinkins, W. G. Maitotoxin and $\mathrm{P} 2 \mathrm{Z} / \mathrm{P} 2 \mathrm{X}_{7}$ purinergic receptor stimulation activate a common cytolytic pore. Am. J. Physiol. 277, C766-C776 (1999).

15. Verhoef, P. A., Kertesy, S. B., Estacion, M., Schilling, W. P. \& Dubyak, G. R. Maitotoxin induces biphasic interleukin- $1 \beta$ secretion and membrane blebbing in murine macrophages. Mol. Pharmacol. 66, 909-920 (2004).

16. $L i, P$. et al. Mice deficient in IL-1 $\beta$-converting enzyme are defective in production of mature IL-1ß and resistant to endotoxic shock. Cell 80, 401-411 (1995).

17. Martinon, F., Agostini, L., Meylan, E. \& Tschopp, J. Identification of bacterial muramyl dipeptide as activator of the NALP3/cryopyrin inflammasome. Curr. Biol. 14, 1929-1934 (2004).

18. Girardin, S. E. et al. Nod2 is a general sensor of peptidoglycan through muramyl dipeptide (MDP) detection. J. Biol. Chem. 278, 8869-8872 (2003).

19. Kobayashi, K. S. et al. Nod2-dependent regulation of innate and adaptive immunity in the intestinal tract. Science 307, 731-734 (2005).

20. Maeda, S. et al. Nod2 mutation in Crohn's disease potentiates NF-кB activity and IL-1beta processing. Science 307, 734-738 (2005).

21. Damiano, J. S., Newman, R. M. \& Reed, J. C. Multiple roles of CLAN (caspase-associated recruitment domain, leucine-rich repeat, and NAIP CIIA HET-E, and TP1-containing protein) in the mammalian innate immune response. J. Immunol. 173, 6338-6345 (2004).

22. Hoffman, H. M. Mueller, J. L, Broide, D. H. Wanderer, A. A. \& Kolodner, R. D. Mutation of a new gene encoding a putative pyrin-like protein causes familial cold autoinflammatory syndrome and Muckle-Wells syndrome. Nature Genet. 29, 301-305 (2001)

23. McDermott, M. F. Genetic clues to understanding periodic fevers, and possible therapies. Trends Mol. Med. 8, 550-554 (2002).

24. Feldmann, J. et al. Chronic infantile neurological cutaneous and articular syndrome is caused by mutations in CIAS1, a gene highly expressed in polymorphonuclear cells and chondrocytes. Am. J. Hum. Genet. 71, 198-203 (2002)

25. Aganna, E. et al. Association of mutations in the NALP3/CIAS1/PYPAF1 gene with a broad phenotype including recurrent fever, cold sensitivity, sensorineural deafness, and AA amyloidosis. Arthritis Rheum. 46, 2445-2452 (2002).

Supplementary Information is linked to the online version of the paper at www.nature.com/nature.

Acknowledgements We thank members of the Dixit laboratory for discussions, and M. Bauer, J. Starks, C. Olsson, M. Osborn, J. Hongo, M. Bever, J. Cupp and H. Maecker for technical assistance. S. aureus strains were provided by T. Foster. L. monocytogenes LLO mutant was provided by D. Portnoy. This work was supported by NIH grants awarded to D.M.M. and a fellowship from the Giannini Family Foundation awarded to D.S.W.

Author Information Reprints and permissions information is available at npg.nature.com/reprintsandpermissions. The authors declare no competing financial interests. Correspondence and requests for materials should be addressed to V.M.D. (dixit@gene.com) 